Canadian

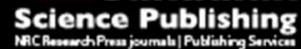

Canadian Journal of Microbiology Revue canadienne de de microbiologie

\title{
Analysis of synonymous codon usage in spike protein gene of infectious bronchitis virus
}

\begin{tabular}{|r|l|}
\hline Journal: & Canadian Journal of Microbiology \\
\hline Manuscript ID & cjm-2015-0418.R1 \\
\hline Manuscript Type: & Note \\
\hline Date Submitted by the Author: & $26-$ Aug-2015 \\
\hline Keyword: & $\begin{array}{l}\text { Kist of Authors: } \\
\text { Kioengineering } \\
\text { Bioengineering }\end{array}$ \\
\hline &
\end{tabular}


1 Analysis of synonymous codon usage in spike protein gene of infectious bronchitis virus

2 Aditi Makhija ${ }^{1}$, Sachin $\operatorname{Kumar}^{1 *}$

3

$4{ }^{1}$ Department of Biosciences and Bioengineering, Indian Institute of Technology Guwahati,

5 Guwahati, Assam 781039, India.

6 * Corresponding author: Mailing address: Department of Biosciences and Bioengineering,

7 Indian Institute of Technology Guwahati, Guwahati, Assam 781039, India.

8 Phone: (91) 3612582229; Fax: (91) 3612582249

$9 \quad$ E-mail: sachinku@iitg.ernet.in

10

11

12

13

14

15

16

17

18

19 


\section{Abstract}

Infectious bronchitis virus (IBV) is responsible for causing respiratory, renal and

22 urogenital disease in poultry. IBV infection in poultry lead to high mortality rates in affected

23 flocks and severe economic losses due to drop in egg production and reduce gain in live 24 weight of the broiler birds. IBV encoded spike protein (S) is the major host protective immunogen. Although the functions of the $\mathrm{S}$ protein have been well studied, the factors shaping synonymous codon usage bias and nucleotide composition in the $\mathrm{S}$ gene have not been reported yet. In the present study, we have analyzed the relative synonymous codon usage and effective number of codons (ENC) using the 53 IBV S genes. The major trend in codon usage variation was studied using correspondence analysis. The plot of ENC values and GC3s as well as the correlation between base composition and codon usage bias suggests that mutational pressure rather than natural selection is the main factor that determines the codon usage bias in $\mathrm{S}$ gene. Interestingly, no association of aromaticity, degree of hydrophobicity and aliphatic index has been observed with the codon usage variation in IBV and provides a basic understanding of the codon usage bias.

\section{Keywords}

40 Mutational pressure; aromaticity; aliphaticity; IBV; evolution. 


\section{Notes:}

Infectious bronchitis (IB) is an acute and highly contagious respiratory disease of poultry that is prevalent throughout the world. Infection of IB can lead to substantial economic losses to the poultry industry worldwide. The causative agent, avian infectious bronchitis virus (IBV) is a group member of the genus Coronavirus under family Coroniviridae. It is commonly found in the respiratory and non-respiratory tissues such as the epithelial lining of the gut, kidney and oviduct of the domestic fowl (Jackwood 2012). The coronaviruses are enveloped and contain an unsegmented, 5'-capped and 3'-polyadenylated, single-stranded, positive-sense RNA genome of 28-32 kb (Boursnell et al. 1987). It replicates in the host cell cytoplasm. The spike glycoprotein $(\mathrm{S})$, a small membrane protein (E) and an integral membrane protein $(\mathrm{M})$ are the three major membrane proteins in coronavirus. The $\mathrm{S}$ protein is a type I glycoprotein composed of three homopolymers that is responsible for binding to the target cell receptor and fusion of the viral and cellular membranes (Casais et al. 2003). The IBV S glycoprotein (1,162 amino acids) is cleaved into two subunits, S1 and S2 of 535 and 627 amino acids, respectively.

IBV is currently controlled by the use of both live attenuated and inactivated vaccines. The IBV S1 subunit can induce neutralising antibodies that are responsible for protecting birds against subsequent IBV infection and associated IB disease. However, many different IBV serotypes have been reported because of the variations in amino acid sequence of the S1 subunit leading to failure of vaccines due to lack of cross-protection (Abro et al. 2012). Moreover, the first and third quarters of the S1 protein is sufficient to induce an effective immune response against IBV infection in birds (Kant et al. 1992). There is overwhelming information suggesting that only a few amino acid differences amongst $S$ proteins are sufficient to have a detrimental impact on cross-protection (Martin et al. 2014; Rimondi et al. 2009; Sun et al. 2007). In addition, genetically engineered IBV vaccines with heterologous 
67 spike protein genes have shown promising results against its infection in poultry (Cavanagh 68 2007).

Viruses such as influenza virus, Newcastle disease virus, infectious bursal disease virus, human cytomegalovirus and porcine reproductive and respiratory syndrome, classical swine fever virus have been extensively studied for synonymous codon usage for their various genes (Deka and Chakraborty 2014; Ding et al. 2014; Hu et al. 2014; Kumar et al. 2015; Kumar and Kumar 2014; Tao et al. 2009; Wang et al. 2011). Although the functions of the $\mathrm{S}$ protein in IBV have been well studied, but extensive synonymous codon usage study has not been reported. The present study is conducted in order to better understand the characteristics of the IBV S gene and to reveal more information regarding the role of aromatic, aliphatic and hydrophobic amino acids in its codon bias.

Codons in genes do not occur at equal frequencies, but follow a synonymous codon usage pattern. In both the prokaryotic and eukaryotic genes, the synonymous codon usage is non-random (Babbitt et al. 2014; Li 1997). It has been postulated that genes in any genome follow the coding pattern in accordance with the synonymous codon and a similar trend of codon usage is seen within an organism and in related species (Butt et al. 2014; Li 1997). Studies on synonymous codon usage depict that they vary not only in different genomes, but also in different genes of the same genome (Grantham et al. 1980). The highly expressed genes have a strong preference for a subset of codons in comparison to the ones that are less expressed which have a uniform set of codon usage (Epstein et al. 2000; Gu et al. 2004). The alternative codons also result in the same protein sequences, but may differ in structure and functions (Li et al. 2011). Factors contributing to codon usage bias include gene expression level, G+C\% composition, GC skew, amino acid conservation, protein hydropathy, transcriptional selection, RNA stability, optimal growth temperature and hyper saline adaptation (Ermolaeva 2001; Kober and Pogson 2013; Lynn et al. 2002; Paul et al. 2008). 
Fifty three complete sequences of S protein genes of IBV isolates were obtained from

93 GenBank (Table 1). The codon usage pattern analysis was performed in the coding sequences of the $\mathrm{S}$ protein gene by inserting a stop codon at the end of every sequence of the gene. The patterns of codon usage were analyzed for $53 \mathrm{~S}$ protein gene sequences of IBV. The calculation of relative synonymous codon usage (RSCU) index enables the characterization of synonymous codon usage and is expressed as the ratio of the observed usage of codons to the expected value (Sharp PM 1993; Sharp and Li 1986). The RSCU values of each codon in each gene were used to measure the synonymous codon usage using Codon W 1.4.2 software. The RSCU value of 1 indicates that the codon is chosen randomly, RSCU $>1$ indicates that the codon is more frequent than expected and $\mathrm{RSCU}<1$ indicates that the codon chosen is 102 less frequent.

RSCU calculation formulae: RSCU $=\left(g_{i j} \times n_{j}\right) /\left(\Sigma_{i j}^{n j} g_{i j}\right)($ Sharp and Li 1986)

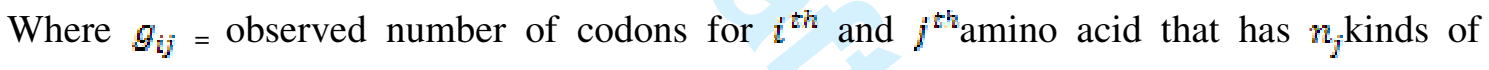
synonymous codon.

The effective number of codons (ENC or Nc) was calculated in Codon W 1.4.2. The ENC is used to quantify the codon usage bias of each gene(Wright 1990).

ENC calculation formulae: $E N C=2+S+\left[29 /\left[S^{2}+(1-5)^{2}\right]\right]$

Where S represents the value of $\mathrm{G}+\mathrm{C}$ at the third position (GC3) (Wright 1990).

The ENC values were correlated to the percentage of GC3s. When codon usage is biased only one for each amino acid is used and the ENC is 20. If the ENC value is 61 then there is no bias in codon usage and all synonymous codons are equally used. The aliphatic index (AI) refers to the relative volume of a protein that is occupied by aliphatic side chains 
114 (Alanine, Isoleucine, Valine and Leucine) and contributes to the increased thermostability 115 observed for globular proteins (Ikai 1980).

$$
\text { AI calculation formulae: } A I-X(A)+a X(V)+[b x(X(I)+X(L)]
$$

Where $\mathrm{X}(\mathrm{A}), \mathrm{X}(\mathrm{V}), \mathrm{X}(\mathrm{I})$ and $\mathrm{X}(\mathrm{L})$ are mole percent of alanine, valine, isoleucine and leucine, respectively. The coefficients $\mathrm{a}, \mathrm{b}$ are relative volumes of $\mathrm{V}(\mathrm{a}=2.9)$ and $\mathrm{L} / \mathrm{I}$ side chains $(b=3.9)$ relative to alanine side chains. The grand average hydropathy (GRAVY) value determines the hydrophobic and hydrophilic properties of proteins. GRAVY is calculated as the sum of the hydropathy values of all the amino acids that are present in a protein divided by the total number of residues (Kyte and Doolittle 1982). The negative values indicate non polar proteins and positive values indicate polar proteins. Correspondence analysis (COA) enables the identification of the major trends in the variation of data and distribution of genes along continuous axes in accordance with these trends. For the major trend to influence codon usage variation in genes the variability should be more than $10 \%$ (Greenacre 1984). The COA of the 53 sequences was performed in Codon W 1.4.2. The correspondence analysis was used to study the variations in codon usage. The major trends studied were the axes of relative inertia.All the statistical analysis was carried out using the statistical analysis software SPSS Statistics Version 20.0. Correlation analysis was performed using Pearson's correlation analysis method with statistical significance at $p$-value $\leq 0.05$ and 0.01 .

The most used codons were U-ended, C-ended and A-ended, whereas, interestingly no G-ended codons were used as preferential codons. The GC3s and GC content of the gene are displayed in table 1 . The RSCU values were calculated to study the variation in codon usage bias in IBV S gene. The details results of RSCU in 53 IBV S genes are displayed in table 2.

137 The average GC3s\% content of IBV S gene was found to be $24.4415 \%$ whereas, GC\% was 
138 found to be $36.33 \%$. The mean GC3 is greater than that of the GC in the isolates of IBV.

139 These results are conclusive of the fact that IBV S gene is not GC rich gene and most codons 140 are A- and U-ended.

The Nc values range from 20 to 61 . The higher the extent of codon preference, the smaller is the Nc value. A gene exhibiting no codon bias has Nc equal to 61. Conversely, in a highly biased gene one codon is used for each amino acid thus Nc equals 20. Our data of IBV

S genes showed that the Nc value varied from 40.15 to 58.98 , with a mean of 44.2413 with a standard deviation of 3.6085, which indicated that the codon usage bias in IBV S gene was small and having less variation.

The COA was performed using Codon $\mathrm{W}$ 1.4.2 to investigate codon usage variation in 
162 the variation in synonymous codon usage in IBV S genes. The patterns of base composition were most likely the results of mutational bias, and not natural selection. The main factors accounting for codon usage variation in genes are thought to be mutational pressure and translational selection (Jenkins and Holmes 2003). To investigate the role of mutational bias as a determinant of codon usage variation in IBV $\mathrm{S}$ genes, correlation analysis was employed to correlate first two axis of COA with codon usage indices. No correlation was observed between the two axes, GRAVY, aromaticity, GC3s and AI (Figure 2).

Aromaticity and hydrophobicity determines the codon usage variation (Lobry and Gautier 1994). In order to investigate whether selection pressure contributes to the codon usage variation among $\mathrm{S}$ genes, a correlation analysis to evaluate whether aromaticity (AROMO) and GRAVY values were related to the first two axes of the COA and codon usage indices was performed. Similarly, we have also performed a correlation analysis of AI with various codon usage indices to study the role of AI in codon bias (Table 3). Our correlation analysis results showed that there was significant correlation observed between AROMO and G+C content of the IBV S gene (Table 3). GRAVY was found to be positively correlated with GC3s $(r=0.700, P<0.001)$ and with ENC (Table 3). There was no significant correlation observed between GRAVY and GC1, GC2, and GC. Nc was found to be positively correlated with GC3s $(r=0.955, p<0.001)$, AI $(r=0.288, p<0.05)$, GC $(r=0.399, P<0.05) \quad$ GRAVY $\quad(r=0.670, P<0.001) \quad$ and AROMO $(r=0.562, P<0.001)$. GC3s were found to be positively correlated with GC $(r=0.495, P<0.001) \quad, \quad$ GRAVY $\quad(r=0.700, P<0.001)$ and AROMO ( $r=0.697, P<0.001)$. GC was found to be positively correlated with NC $(r=0.399, P<0.05)$ GC3s $(r=0.495, P<0.001)$ and $\operatorname{AROMO}(r=0.724, P<0.001 \%$ 

correlated with axis 1 or axis 2 of COA, indicating that the codon usage bias IBV S gene is entirely due to mutational pressure. However, selection pressure for the codon usage pattern in IBV genome cannot be ruled out. The results indicated that the aromaticity, degree of hydrophobicity and aliphatic index have no association with the codon usage variation in IBV

$\mathrm{S}$ genes. The significance of these conclusions remains to be determined. The study will help us to understand the variation in S protein gene and the outbreak of IBV in poultry. Further studies on other genes and its correlation with $\mathrm{S}$ would give a better insight of IBV genome and its codon usage.

\section{Acknowledgments}

We thank Chandra Shekhar Kumar and all our laboratory members for their excellent technical assistance and help. The IBV research in our laboratory is currently supported by the IITG start-up grant.

\section{Conflict of interest:}

The authors declare no conflict of interest. 2012. Emergence of novel strains of avian infectious bronchitis virus in Sweden. Vet Microbiol 155(24): 237-246. doi: S0378-1135(11)00532-3 [pii]10.1016/j.vetmic.2011.09.022. Acids Res. doi: gku811 [pii]10.1093/nar/gku811. 
210 Boursnell, M.E., Brown, T.D., Foulds, I.J., Green, P.F., Tomley, F.M., and Binns, M.M. 1987.

211 Completion of the sequence of the genome of the coronavirus avian infectious bronchitis virus. J

212 Gen Virol 68 ( Pt 1): 57-77.

213 Butt, A.M., Nasrullah, I., and Tong, Y. 2014. Genome-wide analysis of codon usage and influencing

214 factors in chikungunya viruses. PLoS One 9(3): e90905. doi: 10.1371/journal.pone.0090905

215 PONE-D-13-50453 [pii].

216 Casais, R., Dove, B., Cavanagh, D., and Britton, P. 2003. Recombinant avian infectious bronchitis virus

217 expressing a heterologous spike gene demonstrates that the spike protein is a determinant of cell tropism. J Virol 77(16): 9084-9089.

Cavanagh, D. 2007. Coronavirus avian infectious bronchitis virus. Vet Res 38(2): 281-297. doi:

10.1051/vetres:2006055v06178 [pii].

Deka, H., and Chakraborty, S. 2014. Compositional Constraint Is the Key Force in Shaping Codon

Usage Bias in Hemagglutinin Gene in H1N1 Subtype of Influenza A Virus. Int J Genomics 2014: 349139. doi: 10.1155/2014/349139.

Ding, Y.Z., You, Y.N., Sun, D.J., Chen, H.T., Wang, Y.L., Chang, H.Y., Pan, L., Fang, Y.Z., Zhang, Z.W., Zhou, P., Lv, J.L., Liu, X.S., Shao, J.J., Zhao, F.R., Lin, T., Stipkovits, L., Pejsak, Z., Zhang, Y.G., and Zhang, J. 2014. The Effects of the Context-Dependent Codon Usage Bias on the Structure of the nsp1alpha of Porcine Reproductive and Respiratory Syndrome Virus. Biomed Res Int 2014: 765320. doi: $10.1155 / 2014 / 765320$.

Epstein, R.J., Lin, K., and Tan, T.W. 2000. A functional significance for codon third bases. Gene 245(2): 291-298. doi: S0378-1119(00)00042-1 [pii].

Ermolaeva, M.D. 2001. Synonymous codon usage in bacteria. Curr Issues Mol Biol 3(4): 91-97.

Grantham, R., Gautier, C., and Gouy, M. 1980. Codon frequencies in 119 individual genes confirm consistent choices of degenerate bases according to genome type. Nucleic Acids Res 8(9): 18931912. 
236 Gu, W., Zhou, T., Ma, J., Sun, X., and Lu, Z. 2004. The relationship between synonymous codon usage 237 and protein structure in Escherichia coli and Homo sapiens. Biosystems 73(2): 89-97. doi: 238 10.1016/j.biosystems.2003.10.001S0303264703001965 [pii].

239 Hu, C., Chen, J., Ye, L., Chen, R., Zhang, L., and Xue, X. 2014. Codon usage bias in human 240 cytomegalovirus and its biological implication. Gene 545(1): 5-14. doi: S0378-1119(14)00550-2 [pii]

$241 \quad$ 10.1016/j.gene.2014.05.018.

242 Ikai, A. 1980. Thermostability and aliphatic index of globular proteins. J Biochem 88(6): 1895-1898.

243 Jackwood, M.W. 2012. Review of infectious bronchitis virus around the world. Avian Dis 56(4): 634244641.

245 Jenkins, G.M., and Holmes, E.C. 2003. The extent of codon usage bias in human RNA viruses and its 246 evolutionary origin. Virus Res 92(1): 1-7. doi: S016817020200309X [pii].

247 Kant, A., Koch, G., van Roozelaar, D.J., Kusters, J.G., Poelwijk, F.A., and van der Zeijst, B.A. 1992. 248 Location of antigenic sites defined by neutralizing monoclonal antibodies on the S1 avian infectious 249 bronchitis virus glycopolypeptide. J Gen Virol 73 ( Pt 3): 591-596.

250 Kober, K.M., and Pogson, G.H. 2013. Genome-wide patterns of codon bias are shaped by natural 251 selection in the purple sea urchin, Strongylocentrotus purpuratus. G3 (Bethesda) 3(7): 1069-1083. 252 doi: g3.113.005769 [pii]10.1534/g3.113.005769.

253 Kumar, C.S., Hazarika, N.M., and Kumar, S. 2015. Analysis of synonymous codon usage in the VP2 254 protein gene of infectious bursal disease virus. Arch Virol. doi: 10.1007/s00705-015-2505-0.

255 Kumar, C.S., and Kumar, S. 2014. Species based synonymous codon usage in fusion protein gene of 256 Newcastle disease virus. PLoS One 9(12): e114754. doi: 10.1371/journal.pone.0114754

257 PONE-D-14-25870 [pii].

258 Kyte, J., and Doolittle, R.F. 1982. A simple method for displaying the hydropathic character of a 259 protein. J Mol Biol 157(1): 105-132. doi: 0022-2836(82)90515-0 [pii].

260 Li, W.H. 1997. Molecular Evolution. second edition ed. Sinauer Associates, Sunderland. 
261 Li, Y., Wang, C., Cheng, X., Wu, T., and Zhang, C. 2011. Synonymous codon usage of the VP2 gene of a 262 very virulent infectious bursal disease virus isolate serial passaged in chicken embryos. Biosystems 263 104(1): 42-47. doi: S0303-2647(11)00002-5 [pii]10.1016/j.biosystems.2010.12.009.

264 Lobry, J.R., and Gautier, C. 1994. Hydrophobicity, expressivity and aromaticity are the major trends 265 of amino-acid usage in 999 Escherichia coli chromosome-encoded genes. Nucleic Acids Res 22(15): $266 \quad 3174-3180$.

267 Lynn, D.J., Singer, G.A., and Hickey, D.A. 2002. Synonymous codon usage is subject to selection in 268 thermophilic bacteria. Nucleic Acids Res 30(19): 4272-4277.

269 Martin, E.A., Brash, M.L., Hoyland, S.K., Coventry, J.M., Sandrock, C., Guerin, M.T., and Ojkic, D. 270 2014. Genotyping of infectious bronchitis viruses identified in Canada between 2000 and 2013. Avian Pathol 43(3): 264-268. doi: 10.1080/03079457.2014.916395. adaptation: insights from genome and proteome composition of halophilic prokaryotes. Genome Biol 9(4): R70. doi: gb-2008-9-4-r70 [pii]10.1186/gb-2008-9-4-r70. characterization of avian infectious bronchitis virus strains from outbreaks in Argentina (2001-2008). Avian Pathol 38(2): 149-153. doi: 909875258 [pii]10.1080/03079450902737821. York. pp. 378-397. Sharp, P.M., and Li, W.H. 1986. Codon usage in regulatory genes in Escherichia coli does not reflect selection for 'rare' codons. Nucleic Acids Res 14(19): 7737-7749. Massachusetts prototype like coronavirus isolated from wild peafowls is pathogenic to chickens. Virus Res 130(1-2): 121-128. doi: S0168-1702(07)00217-1 [pii]10.1016/j.virusres.2007.06.003. classical swine fever virus. Virus Genes 38(1): 104-112. doi: 10.1007/s11262-008-0296-z. 
287 Wang, M., Liu, Y.S., Zhou, J.H., Chen, H.T., Ma, L.N., Ding, Y.Z., Liu, W.Q., Gu, Y.X., and Zhang, J. 2011.

288 Analysis of codon usage in Newcastle disease virus. Virus Genes 42(2): 245-253. doi: 289 10.1007/s11262-011-0574-z.

290 Wright, F. 1990. The 'effective number of codons' used in a gene. Gene 87(1): 23-29. doi: 0378-

291 1119(90)90491-9 [pii].

292 Zhong, J., Li, Y., Zhao, S., Liu, S., and Zhang, Z. 2007. Mutation pressure shapes codon usage in the 293 GC-Rich genome of foot-and-mouth disease virus. Virus Genes 35(3): 767-776. doi: 10.1007/s11262294 007-0159-z. 


\section{Figure legends}

Figure 1: $\mathrm{N}_{\mathrm{c}}$ of codons used plotted against the GC3s IBV $\mathrm{S}$ gene. The continuous curve as seen in the plot represents the relationship between GC3s and the $\mathrm{N}_{\mathrm{c}}$ in the absence of selection. All the values lie below the expected curve

Figure 2: Scatter plot of value of the first and second axis of each IBV S gene in COA. The first axis accounts for $34.503 \%$ of all variation and the second axis accounts for $25.245 \%$ of total variation. 
Figure 1:

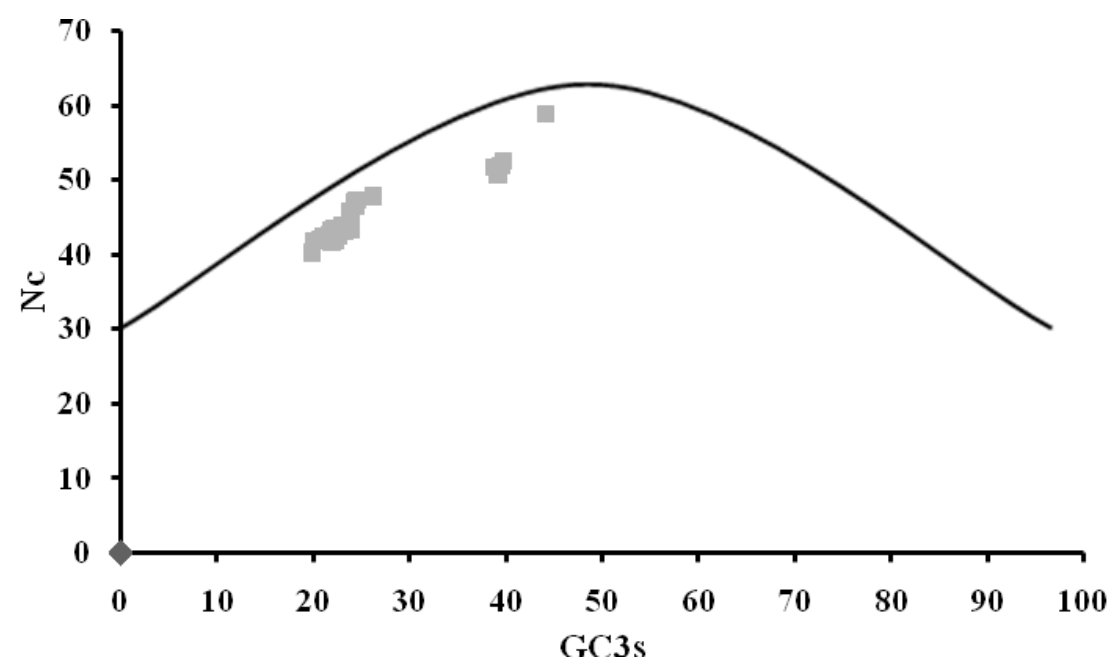


Figure 2:

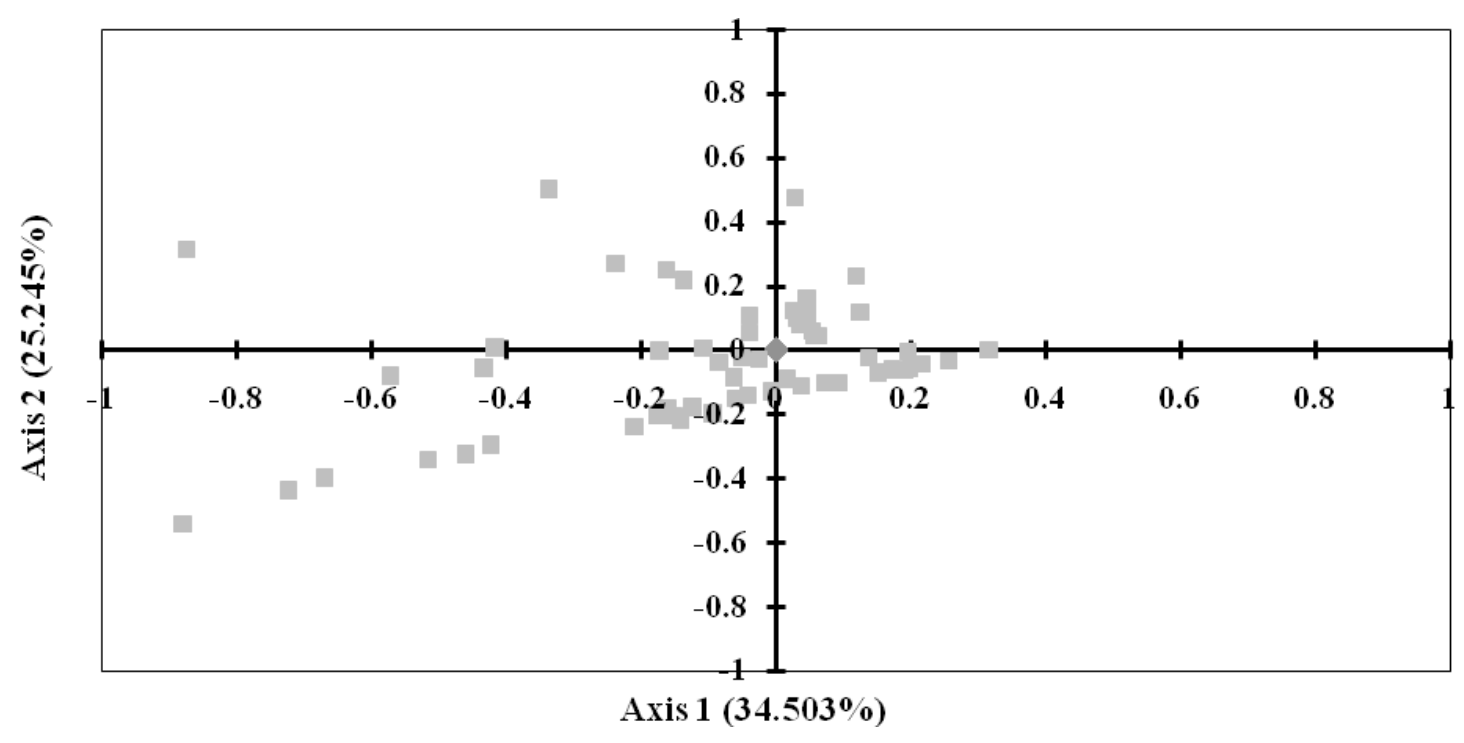

https://mc06.manuscriptcentral.com/cjm-pubs 


\section{TABLES:}

Table 1. List of infectious bronchitis virus spike gene used for analysis of synonymous codon usage in the study. Bold letters indicates the lower and higher value of Nc.

\begin{tabular}{|c|c|c|c|c|c|c|c|c|}
\hline \multirow[b]{2}{*}{ S.No } & \multirow[b]{2}{*}{ Accession Number } & \multicolumn{4}{|c|}{ Mononucleotide frequencies $(\%)$} & \multirow[b]{2}{*}{$\mathrm{Nc}$} & \multirow[b]{2}{*}{ GC3s(\%) } & \multirow[b]{2}{*}{ GC(\%) } \\
\hline & & T3s & C3s & A3s & G3s & & & \\
\hline 1 & A12747 & 39.36 & 29.82 & 38.99 & 19.49 & 51.83 & 39 & 38.90 \\
\hline 2 & AY31930 & 65.33 & 12.05 & 30.81 & 13.83 & 40.15 & 19.9 & 35.60 \\
\hline 3 & AY338732 & 31.75 & 18.74 & 39.71 & 32.55 & 52.67 & 39.7 & 37.20 \\
\hline 4 & AY702975 & 62.02 & 10.92 & 34.59 & 16.98 & 42.08 & 20.7 & 35.40 \\
\hline 5 & AY761141 & 61.61 & 12.76 & 32.89 & 16.38 & 41.74 & 22 & 36.10 \\
\hline 6 & AY189157 & 60.28 & 13.10 & 32.69 & 18.22 & 43.66 & 23.5 & 36.40 \\
\hline 7 & AY692454 & 61.38 & 12.44 & 33.61 & 16.13 & 42.16 & 21.6 & 36.20 \\
\hline 8 & AY702085 & 61.47 & 12.98 & 32.93 & 16.25 & 42.45 & 22.1 & 36.20 \\
\hline 9 & DQ068701 & 58.73 & 13.15 & 33.65 & 18.47 & 44.75 & 23.9 & 37.00 \\
\hline 10 & DQ490205 & 59.68 & 13.17 & 34.75 & 18.02 & 43.18 & 23.2 & 36.10 \\
\hline 11 & DQ490206 & 38.86 & 31.09 & 39.97 & 18.40 & 50.78 & 39.3 & 39.40 \\
\hline 12 & DQ490209 & 60.41 & 12.39 & 34.54 & 17.48 & 43.64 & 22.4 & 36.30 \\
\hline 13 & DQ490210 & 61.49 & 12.40 & 33.77 & 16.38 & 42.51 & 21.7 & 36.20 \\
\hline 14 & DQ490211 & 61.03 & 12.59 & 33.89 & 16.73 & 43.08 & 22.1 & 36.20 \\
\hline 15 & DQ490212 & 52.87 & 15.11 & 38.79 & 20.13 & 47.67 & 26.2 & 36.60 \\
\hline 16 & DQ490213 & 61.43 & 12.49 & 33.73 & 16.45 & 42.57 & 21.8 & 36.10 \\
\hline 17 & DQ490214 & 59.53 & 14.40 & 33.29 & 17.38 & 44.18 & 24 & 36.40 \\
\hline 18 & DQ490215 & 59.59 & 13.50 & 34.70 & 17.84 & 43.11 & 23.4 & 36.20 \\
\hline 19 & DQ490216 & 60.41 & 13.27 & 34.18 & 17.22 & 43.08 & 22.9 & 36.20 \\
\hline 20 & DQ490217 & 60.16 & 13.25 & 34.70 & 17.04 & 42.59 & 22.7 & 36.00 \\
\hline 21 & DQ490218 & 61.49 & 12.46 & 33.41 & 16.51 & 42.7 & 21.9 & 36.20 \\
\hline 22 & DQ490219 & 55.31 & 15.57 & 38.15 & 17.05 & 47.13 & 24.5 & 36.30 \\
\hline 23 & |DQ490221 & 61.29 & 12.40 & 34.05 & 16.38 & 42.6 & 21.7 & 36.10 \\
\hline 24 & DQ646404 & 59.48 & 13.04 & 35.19 & 16.07 & 43.21 & 22.1 & 36.10 \\
\hline 25 & DQ646406 & 60.18 & 12.54 & 35.18 & 16.11 & 42.49 & 21.6 & 36.00 \\
\hline
\end{tabular}




\begin{tabular}{|c|c|c|c|c|c|c|c|c|}
\hline 26 & DQ490207 & 55.53 & 15.49 & 38.24 & 17.08 & 46.58 & 24.4 & 36.10 \\
\hline 27 & DQ490208 & 60.36 & 12.68 & 33.17 & 17.98 & 43.56 & 23.1 & 36.50 \\
\hline 28 & DQ490220 & 55.31 & 15.57 & 37.91 & 17.32 & 47.33 & 24.7 & 36.30 \\
\hline 29 & EU822336 & 60.14 & 12.71 & 34.62 & 16.78 & 42.72 & 22.3 & 36.10 \\
\hline 30 & EU822337 & 59.76 & 12.13 & 34.20 & 18.08 & 43.09 & 22.8 & 36.50 \\
\hline 31 & EU822338 & 58.62 & 13.63 & 33.74 & 17.98 & 43.42 & 23.9 & 36.90 \\
\hline 32 & EU822339 & 60.34 & 12.37 & 33.98 & 17.44 & 43.24 & 22.4 & 36.20 \\
\hline 33 & EU822340 & 58.73 & 13.22 & 33.85 & 18.46 & 43.96 & 23.9 & 36.80 \\
\hline 34 & EU822341 & 61.63 & 12.79 & 32.93 & 16.36 & 41.9 & 22 & 36.10 \\
\hline 35 & FJ829873 & 61.93 & 11.98 & 33.17 & 16.67 & 41.94 & 21.5 & 36.10 \\
\hline 36 & FJ829875 & 62.01 & 12.06 & 33.37 & 16.13 & 41.81 & 21.3 & 36.00 \\
\hline 37 & FJ829878 & 62.22 & 11.82 & 33.37 & 16.06 & 42.2 & 21 & 35.90 \\
\hline 38 & FJ829880 & 61.85 & 12.35 & 33.01 & 16.03 & 42.15 & 21.5 & 36.20 \\
\hline 39 & FJ829881 & 62.02 & 11.92 & 33.33 & 16.17 & 41.94 & 21.2 & 36.00 \\
\hline 40 & FJ829882 & 60.76 & 12.41 & 33.91 & 17.05 & 42.9 & 22.1 & 36.00 \\
\hline 41 & FJ829883 & 61.94 & 12.35 & 33.54 & 15.83 & 42.22 & 21.2 & 35.80 \\
\hline 42 & FJ829872 & 60.47 & 12.44 & 32.93 & 18.34 & 43.7 & 23 & 36.30 \\
\hline 43 & FJ829874 & 61.54 & 12.75 & 33.01 & 16.26 & 42.09 & 21.9 & 36.10 \\
\hline 44 & FJ829877 & 62.12 & 12.02 & 33.41 & 15.83 & 42.28 & 21 & 35.90 \\
\hline 45 & FJ829879 & 61.62 & 12.22 & 33.21 & 16.42 & 42.3 & 21.6 & 36.10 \\
\hline 46 & GQ229232 & 59.41 & 13.97 & 34.42 & 16.69 & 43.36 & 23.2 & 36.40 \\
\hline 47 & GU386375 & 61.74 & 12.85 & 33.33 & 16.11 & 41.7 & 21.8 & 36.00 \\
\hline 48 & JF732918 & 57.00 & 12.98 & 37.45 & 19.73 & 45.57 & 24 & 35.70 \\
\hline 49 & KF188436 & 61.63 & 12.79 & 32.53 & 16.73 & 41.93 & 22.3 & 36.30 \\
\hline 50 & M21515 & 42.86 & 12.24 & 26.09 & 50.00 & 58.98 & 44.1 & 33.30 \\
\hline 51 & U49858 & 39.91 & 30.16 & 38.36 & 20.72 & 51.96 & 39.6 & 38.70 \\
\hline 52 & U04739.1 & 39.91 & 29.99 & 38.42 & 20.57 & 52.01 & 39.4 & 38.70 \\
\hline 53 & X87238.1 & 60.60 & 12.06 & 37.21 & 14.84 & 41.94 & 20.3 & 35.00 \\
\hline
\end{tabular}


Table 2. Infectious bronchitis virus spike gene specific synonymous codon usage. The RSCU is cumulative relative synonymous codon usage. The overall values depict the codon usage for the $\mathrm{S} 1$ gene for all 53 isolates.

\begin{tabular}{|c|c|c|c|c|}
\hline Amino acid & Codon & Codon Repeat & RSCU & $\begin{array}{c}\begin{array}{c}\text { Codons predominantly used in S protein } \\
\text { gene }\end{array} \\
\text {. }\end{array}$ \\
\hline \multirow[t]{2}{*}{ Phe } & UUU & 2880 & 1.6970 & \multirow[t]{2}{*}{ UUU } \\
\hline & UUC & 536 & 0.3030 & \\
\hline \multirow[t]{2}{*}{ Leu } & UUA & 1440 & 1.7136 & \multirow[t]{2}{*}{ UUA } \\
\hline & UUG & 1110 & 1.3679 & \\
\hline \multirow[t]{2}{*}{ Tyr } & UAU & 2272 & 1.3830 & \multirow[t]{2}{*}{ UAU } \\
\hline & UAC & 1013 & 0.6170 & \\
\hline \multirow[t]{4}{*}{ Leu } & CUU & 1365 & 1.6255 & \multirow[t]{4}{*}{$\mathbf{C U U}$} \\
\hline & CUC & 249 & 0.2908 & \\
\hline & CUA & 529 & 0.6089 & \\
\hline & CUG & 322 & 0.3947 & \\
\hline \multirow[t]{2}{*}{ His } & CAU & 563 & 1.2687 & \multirow[t]{2}{*}{$\overline{C A U}$} \\
\hline & CAC & 333 & 0.7313 & \\
\hline \multirow[t]{2}{*}{ Gln } & CAA & 1642 & 1.2013 & \multirow[t]{2}{*}{ CAA } \\
\hline & CAG & 1118 & 0.7987 & \\
\hline \multirow[t]{3}{*}{ Ile } & AUU & 2089 & 1.6368 & \multirow[t]{3}{*}{ AUU } \\
\hline & AUC & 382 & 0.3192 & \\
\hline & AUA & 1341 & 1.0434 & \\
\hline \multirow[t]{2}{*}{ Asn } & AAU & 3450 & 1.6525 & \multirow[t]{2}{*}{$\mathbf{A A U}$} \\
\hline & AAC & 643 & 0.3474 & \\
\hline \multirow[t]{2}{*}{ Lys } & AAA & 1283 & 1.0670 & AAA \\
\hline & AAG & 1103 & 0.9330 & \\
\hline Val & GUU & 2367 & 2.0928 & GUU \\
\hline & GUC & 379 & 0.3504 & \\
\hline & GUA & 973 & 0.8619 & \\
\hline & GUG & 768 & 0.6942 & \\
\hline Asp & GAU & 1522 & 1.2947 & GAU \\
\hline & GAC & 711 & 0.76675 & \\
\hline Glu & GAA & 1277 & 1.2666 & GAA \\
\hline & GAG & 691 & 0.7334 & \\
\hline Ser & UCU & 2000 & 2.0045 & UCU \\
\hline & UCC & 289 & 0.3225 & \\
\hline & UCA & 1166 & 1.3385 & \\
\hline & UCG & 134 & 0.1526 & \\
\hline Cys & UGU & 1558 & 1.5326 & UGC \\
\hline & UGC & 536 & 0.4674 & \\
\hline Pro & $\mathrm{CCU}$ & 1138 & 2.1166 & $\mathbf{C C U}$ \\
\hline & $\mathrm{CCC}$ & 149 & 0.2975 & \\
\hline & CCA & 697 & 1.2860 & \\
\hline & CCG & 167 & 0.3004 & \\
\hline Arg & $\mathrm{CGU}$ & 618 & 2.0240 & CGU \\
\hline & CGC & 44 & 0.1204 & \\
\hline & CGA & 96 & 0.2779 & \\
\hline & CGG & 46 & 0.1183 & \\
\hline Thr & $\mathrm{ACU}$ & 2383 & 2.1072 & $\mathbf{A C U}$ \\
\hline & ACC & 425 & 0.4077 & \\
\hline & ACA & 1306 & 1.1951 & \\
\hline & ACG & 297 & 0.2906 & \\
\hline Ser & AGU & 1588 & 1.8217 & AGU \\
\hline & AGC & 292 & 0.3609 & \\
\hline Arg & AGA & 785 & 2.4515 & AGA \\
\hline & AGG & 316 & 0.8942 & \\
\hline Ala & GCU & 1527 & 1.6687 & GCU \\
\hline & GCC & 503 & 0.5809 & \\
\hline & GCA & 1228 & 1.4089 & \\
\hline & GCG & 230 & 0.2670 & \\
\hline Gly & GGU & 2352 & 2.2142 & GGU \\
\hline & GGC & 701 & 0.7198 & \\
\hline & GGA & 659 & 0.6591 & \\
\hline & GGG & 310 & 0.4006 & \\
\hline
\end{tabular}


Table 3. Summary of correlation analysis between the first two axes in COA, GC3s, GRAVY, aromaticity and aliphatic Index (AI) in the selected complete spike gene sequences for infectious bronchitis virus isolates. $P$-value $\leq 0.05 ; P$-value $\leq 0.01$ were used for the correlation analysis

\begin{tabular}{|l|l|l|l|l|l|l|l|}
\hline \multicolumn{2}{|c|}{} & Nc & GC3s & AI & GC & Gravy & Aromo \\
\hline \multirow{2}{*}{ Axis 1 } & $\mathrm{r}$ & .010 & .034 & -.119 & .058 & .070 & .044 \\
\cline { 2 - 8 } & $\mathrm{p}$ & .942 & .811 & .397 & .681 & .619 & .755 \\
\hline Axis 2 & $\mathrm{r}$ & -.040 & .001 & -.021 & .097 & .043 & .065 \\
\cline { 2 - 8 } & $\mathrm{p}$ & .776 & .991 & .884 & .491 & .762 & .645 \\
\hline
\end{tabular}

